\title{
EFFECT OF AN EDUCATIONAL PROGRAM FOR ADOLESCENTS WITH EPILEPSY ON THEIR QUALITY OF LIFE AND SELF-MANAGEMENT SKILLS ${ }^{1}$ Ghada Gamal Mohamed Badawy, ${ }^{2}$ Fawzia El-sayed Abusaad, and $^{3}$ Sahar Farouk Hashem \\ ${ }^{1}$ Assistant Lecturer, Pediatric Nursing Department, Faculty of Nursing, Mansoura University \\ ${ }^{2}$ Professor of Pediatric Nursing, Faculty of Nursing, Mansoura University \\ ${ }^{3}$ Lecturer of Pediatric Nursing, Faculty of Nursing, Mansoura University E-mail of corresponding author ghada_2009@mans.edu.eg
}

\begin{abstract}
Epilepsy is a chronic neurological disorder, which restricts the patient in a range of activities, it has a profound effect on the health and quality of life. Epilepsy may limit the development of independence, social functioning and peer relationships, especially for adolescents it considered a powerful trigger of many psychological and social problems. The pediatric nurse has an important role in helping adolescents to overcome these problems through developing a strategy ensuring the adherence to self-management skills which consequently improve their quality of life. This study aimed to evaluate the effect of an educational program for adolescents with epilepsy on their quality of life and selfmanagement skills. Design: Quasi-experimental design for one group was utilized in carrying out the study at the Pediatric Neurological Unit and Epilepsy Clinic of Mansoura University Children's Hospital, on a sample of 55 adolescents diagnosed with epilepsy for at least 6 months. Data collection Tools: Data were collected by using three tools: Structured Interview Questionnaire Sheet, Quality of Life in Epilepsy for Adolescents Questionnaire and Epilepsy Self-Management Scale. Results: There was statistically significant positive correlation between the studied adolescents' total QOL scores and their total self-management skills scores before implementing the educational program, and after $3 \& 6$ months of the program implementation. Conclusion: Adolescents with epilepsy had better quality of life and self-management skills after implementation of the educational program. Recommendations: Regular and continuous health educational programs are essential for improving the adolescents' QOL and self-management skills.
\end{abstract}

Keywords: Adolescents, Epilepsy, Quality of life, Self-management, Educational program

\section{Introduction:}

Epilepsy is the most common neurological disorder among children and adolescents; it is the second common disease among chronic nervous diseases next to stroke which affects approximately over 50 million patients worldwide (Gavvala \& Schuele, 2016). Epilepsy in adolescence adds to the challenge of transitioning from childhood into adulthood and move away from depending on others to begin to take care of themselves, developing independence is

inhibited, education is at a decisive stage, employment prospects is just being realized, and concerns of relationships, contraception, pregnancy, and parenthood are increasingly progressing. The impact of the disease on the adolescent and on all family members may be profound even when epilepsy is relatively mild. Adequate control achieved before adolescent social and vocational responsibilities can protect from these associated problems (Wilson, 2017). 


\begin{abstract}
Successful management of epilepsy is fundamental for academic functioning during adolescence, psychosocial development, and improving health-related quality of life (HRQOL). Treating seizures successfully and preventing unexpected consequences requires a collaborative effort between health care team, adolescent patients with epilepsy, and their families (Smith\& Wallace, 2016). Epilepsy management covers a variety of ways that further than seizure control with fewer treatment side effects. These ways involve social and psychological interventions to assist adolescents with epilepsy to lead a normal life and reduce the impacts of the disease and treatment on their quality of life. Therefore, to provide a comprehensive management to the patients, quality of life assessment should be an element of the clinical assessment of professionals and believed to be a vital outcome measure for them (Zashikhina $\&$ Hagglof, 2014).
\end{abstract}

As adolescents with epilepsy struggle with their epilepsy and developmental dilemma, their health care providers must shift from the family-centered, nurturing approach of pediatrics to the most autonomous, individualistic style of adult health care. Knowledge needs of adolescents vary depending on the types and severity of seizures, domains specific to epilepsy self-management related to safety concerns, seizure triggers, managing seizures, medications and treatments, and co-morbidities should be covered (Yadegary, Maemodan, Nayeri\& Ghanjekhanlo, 2015; Alfstad et al. 2016).

Educating patients and families about epilepsy was done for many years by health professionals using different strategies and supporting materials, however, it was in an informal manner. However, formal education programs and models have been developed only in recent decades, that concentrate on strategies of self-management to get better well-being, quality of life, and health outcomes (Kerr, Nixon\& Angalakuditi, 2011). Selfmanagement, enabling adolescents with epilepsy to cope with their disease and to lead better quality lives, and helps them to improve their self-efficacy. Strategies implementing the chronic care model, which encourages active patient participation in their health care and selfmanagement behaviors, also can reduce utilization of health care services and minimize health care expenditure (Lewis, Noyes \& Hastings, 2014).

The Pediatric nurse assumes a vital role in providing a comprehensive epilepsy education. Age-related needs necessitate an ongoing assessment and intervention, as epilepsy may occur at any time throughout life. The primary approach is to frame an individualized educational plan of care. Adolescents with epilepsy need accurate and adequate information to help them understand the nature of their illness, drug regimen and restrictive activities that lower the seizure threshold. Epilepsy specialist nurses should provide continuous educational programs about the disease and its management. This will increase adolescents' knowledge, improve their self-efficacy to care for themselves, enhance their quality of life, and possibly reduce patient mortality rates (Bell \& Liu, 2016).

\section{Aim of the study}

The study aimed to evaluate the effect of an educational program for adolescents with epilepsy on their quality of life and self-management skills.

\section{Research hypothesis:}

- Adolescents with epilepsy receiving an educational program will have a better quality of life after implementation of the program.

- Self-management skills of the adolescents with epilepsy will be 
EFFECT OF AN EDUCATIONAL PROGRAM FOR etc...

improved program
implementation.
Subjects and Method
Design:
Pretest-Posttest quasi-experimental
design was utilized in the study
implementation.
Setting: Study was conducted at the
Pediatric Neurological Unit and Epilepsy
Clinic of Mansoura University Children's
Hospital.
Subjects:
A purposive sample of 55 adolescents
attending the previously mentioned
settings after meeting the following
criteria:
- The age ranged from $11-18$ years.
- They are diagnosed with epilepsy for
at least 6 months.
- They were able to read and write.
- They had a regular attendance at the
out-patient clinic.

Tools: The data were collected by three tools as the following:

\section{Tool (I): Structured Interview Questionnaire Sheet}

This tool was developed by the researcher after reviewing the related literature. Questions were in the form of multiple choice questions. This tool was used before program implementation and follow-up for criteria of epileptic seizures were done after three \& six months of program implementation. This questionnaire included two parts:

Part I: Characteristics of adolescents include:

- Sociodemographic characteristics such as, age, sex, residence, birth order, level of education.

- Adolescent's medical history as: The onset of epilepsy, duration, frequency of seizures, and history of hospital admission.

Part II: Criteria of epileptic seizures, including: Awareness of aura symptoms,

seizure duration, frequency of seizures and periods since last seizures.

Tool (II): Quality of Life in Epilepsy for Adolescents Questionnaire (QOLIE AD - 48): Developed by Carmer et al. (1999), it evaluates the quality of life in adolescents with epilepsy from the age of 11 - 18 years. The QOLIE-AD-48 contains 48 items in eight subscales: epilepsy impact (12 items), memory/concentration (10), attitudes toward epilepsy (4), physical functioning (5), stigma (6), social support (4), school behavior (4), and health perceptions (3). The adolescents answered the questions using the Likert scale (1-5), five point Likert scale for forty-two items ( 5 for the best status and 1 for the worse) and a four point Likert Scale for 6 items (4 for the best status and 1 for the worse). Raw scores are translated into scores on a 0-100 response scale. Each subscale mean value of the items was calculated. The total (summary) score is obtained by adding the values for all subscales with a mean of 50 to represent linear transformations for the cohort evaluated. More favorable quality of life reflected by higher total scores (Cramer et al. 1999).

Tool (III): Epilepsy Self-Management Scale: The Epilepsy Self-Management Scale (ESMS) developed by DiIorio et al. (2004), it contained (38) items that assess the frequency of use of epilepsy selfmanagement practices. The aspects of this scale were medication management (10 items), Information ( 8 items), safety (8 items), seizures (6 items) and lifestyle (6 items). Each item is rated on a 5-point scale ranging from (1), never, to (5), always. The scale will be completed by the adolescents with the help of their parents if needed. The tool contains 38 items in a five point rating scale format ranging from one to five. Score of (1) indicated that the patient does not use self-management for 
that item. Score of (5) showed that the patient always uses self-management for that item. Only one item about "drinking alcoholic" was replaced by "I smoke cigarettes" because alcohol consumption is not prevalent in the Egyptian culture. Total scores of epilepsy self-management scale were 190 marks classified as: high for score $75 \%$ and more, moderate for score 50 to less than $75 \%$, low for a score less than $50 \%$. Higher scores indicated higher levels of self-management.

\section{Methods:}

- Before conducting this study, an official approval was obtained from the responsible authorities.

- The developed tools were tested for their reliability using Alpha Cronbach's coefficient test. The alpha reliability for tool (1) was 0.785 , tool (2) was 0.876 and the tool (3) was 0.88 .

- The educational program was prepared by the researcher. It was specially designed in a simple Arabic language to meet the needs of adolescents with epilepsy.

- An informed oral consent was gained from adolescents with epilepsy and their parents after explaining the purpose of the study.

- Adolescents' right to withdraw from the study at any time was ascertained as well as the confidentiality of data and anonymity.

\section{Statistical Analysis}

- Organizing, categorizing, tabulating and analyzing the collected data was done by using SPSS software version 16.

- Presenting the data were done in tables and graphs as frequencies and percentages.

- A significant finding indicated when the $\mathrm{P}$ value of $<0.05$

- Comparison of categorical variables was done using the Chi square test $\left(\mathrm{X}^{2}\right)$ and for continuous quantitative variables using student $t$ test.
- Correlation of the scores was tested using Pearson's correlation.

\section{Results}

Socio-demographic characteristics of adolescents are presented in Table (1). It is revealed from the table that, more than half $(52.7 \%)$ of the studied adolescents were in the age 11 to less than 14 years, while $47.3 \%$ were in the age 14 to 18 years with a mean age $13.96 \pm 2.05$. Slightly more than half of the adolescents were females $(52.7 \%)$. Two third of adolescents were residing in rural area $(65.5 \%)$. Less than half $(45.0 \%$ and $41.8 \%$, respectively) of the adolescents were in preparatory and secondary schools. More than half of the studied adolescents $(56.4 \%)$ were the first child, while $25.5 \%$ were the second. The adolescents' source of information regarding epilepsy revealed from the table in which $40.0 \%$ of them depends on their own experience as the source of their information, while the nurse was the source of information for only one quarter of the adolescents $(25.0 \%)$.

Table (2) clarified the medical history of children with epilepsy. It is revealed from this table that, slightly more than half $(52.7 \%)$ of the adolescents had their first epileptic attack at the age from 1 to 5 years, while only $9.1 \%$ of them had it after 10 years with a mean age of 5.31 3.50 . The majority of adolescents $(89.9 \%)$ has generalized types of epilepsy and only $10.1 \%$ of them have focal types of epilepsy. Also more than two third of adolescents $(78.2 \%)$ used a poly-therapy for the treatment of epilepsy.

It was found from this table that, more than three fourths of the studied adolescents (76.4\%) had a negative family history of epilepsy. Concerning the previous hospitalization of the epileptic adolescents in the last year, it was found that, slightly more than half of the epileptic adolescents (52.7\%) had a previous hospitalization due to epileptic seizures. Less than half of the studied 
EFFECT OF AN EDUCATIONAL PROGRAM FOR etc...

adolescents (44.8\%) were hospitalized once in the last year compared to $41.4 \%$ who were hospitalized for two times.

Criteria of epileptic seizures of the studied adolescents with epilepsy before and follow-up after 3 and 6 months of program implementation are presented in Table (3). It is revealed from the table that, more than half of the adolescents $(56.4 \%)$ were aware of an aura symptom before the epileptic attack before the educational program implementation and their awareness increased after 3 months of the program implementation to reach $70.9 \%$. About two third of the studied adolescents $\quad(64.5 \%$ and $65.5 \%$, respectively) reported that their aura symptoms help in preparation for the epileptic seizures and their seizure duration less than 5 minutes before the program implementation, while this percent changed after implementation of the educational program by 6 months to include the most majority of them $(94.7 \%$ and $90.0 \%$ respectively).

Concerning the frequency of epileptic seizures, it had recurrent once or more / day in $56.4 \%$ of the adolescents before the program implementation, compared to daily recurrence of $72.7 \%$ after 6 months of the program implementation. Regarding the period since the last seizure, the table showed that only $3.6 \%$ of adolescents did not have an epileptic seizure for a period more than one month, while the percentage increased to $63.3 \%$ after 6 months of program implementation respectively. There were a statistically significant difference between epileptic seizures criteria before \& after 3 and 6 months of the program implementation.

Figure (1) illustrates the total level of the studied adolescent's QOL before and follow-up after $3 \& 6$ months of program implementation. It is indicated that only $25.5 \%$ of them had "high" level of their total QOL before the program implementation, compared to $69.1 \%$ and
$58.2 \%$ following the educational program with 3 \& 6 months respectively. There were statistically significant differences between their total quality levels before and after $3 \& 6$ months, and between their total quality levels after 3 and 6 months later.

Total levels of self-management skills of the studied adolescents before and follow-up after $3 \& 6$ months of program implementation are clarified in Figure (2). The table noted the total scores level of the adolescents' self-management skills, it is revealed that the majority of them $(87.3 \%)$ had "low" total self-management skills before the program implementation with a mean of $83.02 \pm 7.87$, compared to $92.7 \%$ and $81.8 \%$ with a mean of $117.82 \pm 15.29$ \& $113.02 \pm 16.11$ respectively had "moderate" level after 3 and 6 months of the program implementation. There were statistical significant differences between the adolescents' total scores level of selfmanagement skills before and after $3 \& 6$ months and between their selfmanagement total scores level after 3 and 6 months of program implementation.

Table (4) presented the correlation between the adolescents' total QOL scores \& their total self-management skills scores. The table pointed that there was statistically significant positive correlation between the studied adolescents' total QOL scores and their total selfmanagement skills scores before implementing the educational program $(\mathrm{r}=0.405, \mathrm{p}=0.002 *)$, and after $3 \& 6$ months of the program implementation $\left(\mathrm{r}=0.774, \quad \mathrm{p}=0.000^{*}\right.$ and $\mathrm{r}=0.761$, $\mathrm{p}=0.000 *$, respectively). 
Ghada Gamal Mohamed Badawy et. al.

Table (1).Socio-demographic Characteristics of the Adolescents with Epilepsy

\begin{tabular}{|c|c|c|}
\hline Characteristics & $\begin{array}{c}\text { No } \\
(n=55)\end{array}$ & $\%$ \\
\hline \multicolumn{3}{|l|}{ Child age / years } \\
\hline$-\quad 11-<14$ & 29 & 52.7 \\
\hline$-\quad 14-\leq 18$ & 26 & 47.3 \\
\hline $\begin{array}{c}\text { Range } \\
\text { Mean } \pm \text { SD }\end{array}$ & \multicolumn{2}{|c|}{$\begin{array}{c}11-18 \\
\mathbf{1 3 . 9 6} \pm \mathbf{2 . 0 5}\end{array}$} \\
\hline \multicolumn{3}{|l|}{ Gender } \\
\hline - Male & 26 & 47.3 \\
\hline - Female & 29 & 52.7 \\
\hline \multicolumn{3}{|l|}{ Residence } \\
\hline - Rural & 36 & 65.5 \\
\hline - Urban & 19 & 34.5 \\
\hline \multicolumn{3}{|l|}{ Education } \\
\hline - Primary & 7 & 12.7 \\
\hline - Preparatory & 25 & 45.5 \\
\hline - Secondary & 23 & 41.8 \\
\hline \multicolumn{3}{|l|}{ Child hobbies \# } \\
\hline $\begin{array}{l}\text { Computer } \\
\text { related } \\
\text { activities }\end{array}$ & 41 & 68.3 \\
\hline $\begin{array}{l}\text { - Watching } \\
\text { T.V }\end{array}$ & 38 & 63.3 \\
\hline $\begin{array}{l}\text { - Physical } \\
\text { activities }\end{array}$ & 13 & 21.7 \\
\hline $\begin{array}{l}\text { Social } \\
\text { activities }\end{array}$ & 2 & 3.3 \\
\hline \multicolumn{3}{|l|}{$\begin{array}{l}\text { Source of } \\
\text { information \# }\end{array}$} \\
\hline $\begin{array}{l}\text {-Own } \\
\text { experience }\end{array}$ & 24 & 40.0 \\
\hline -Parents & 18 & 30.0 \\
\hline -Nurse & 15 & 25.0 \\
\hline -Friends & 3 & 5.0 \\
\hline -Media & 0 & 0.0 \\
\hline
\end{tabular}

\# More than one answer
Table (2): The Medical History of the Studied Adolescents with Epilepsy

\begin{tabular}{|c|c|c|}
\hline Medical history & $\begin{array}{c}\text { No } \\
(n=55)\end{array}$ & $\%$ \\
\hline \multicolumn{3}{|l|}{$\begin{array}{l}\text { Age at first epileptic } \\
\text { attack }\end{array}$} \\
\hline $\begin{array}{ll} & \text { Birth-5 } \\
& \text { years }\end{array}$ & 29 & 52.7 \\
\hline - 6-10 years & 21 & 38.2 \\
\hline - $\quad>10$ years & 5 & 9.1 \\
\hline $\begin{array}{c}\text { Range } \\
\text { Mean } \pm \text { SD }\end{array}$ & \multicolumn{2}{|c|}{$\begin{array}{c}1-14 \\
\mathbf{5 . 3 1} \pm \mathbf{3 . 5 0} \\
\end{array}$} \\
\hline $\begin{array}{cc}\text { Type of seizures } \\
\text { - } \quad \text { Generalized } \\
\text { - } \quad \text { Partial }\end{array}$ & $\begin{array}{c}49 \\
6\end{array}$ & $\begin{array}{l}89.1 \\
10.9\end{array}$ \\
\hline \multicolumn{3}{|l|}{ Type of therapy } \\
\hline $\begin{array}{l}\text { - } \begin{array}{l}\text { Mono- } \\
\text { therapy }\end{array} \\
\end{array}$ & 12 & 21.8 \\
\hline $\begin{array}{l}\text { - Poly- } \\
\text { therapy }\end{array}$ & 43 & 78.2 \\
\hline \multicolumn{3}{|l|}{$\begin{array}{lr}\text { Family } & \begin{array}{r}\text { member } \\
\text { suffering } \\
\text { epilepsy }\end{array} \\
\end{array}$} \\
\hline - Yes & 13 & 23.6 \\
\hline - No & 42 & 76.4 \\
\hline \multicolumn{3}{|l|}{$\begin{array}{l}\text { Hospitalization in } \\
\text { the last year due to } \\
\text { seizures }\end{array}$} \\
\hline - Yes & 29 & 52.7 \\
\hline - $\quad$ No & 26 & 47.3 \\
\hline $\begin{array}{l}\text { Number of previous } \\
\text { hospitalization in } \\
\text { the last year }\end{array}$ & $\mathrm{n}=\mathbf{2 9}$ & \\
\hline - Once & 13 & 44.8 \\
\hline - $\quad$ Twice & 12 & 41.4 \\
\hline $\begin{array}{l}\text { - Three \& } \\
\text { more }\end{array}$ & 4 & 13.8 \\
\hline
\end{tabular}

\# More than one answer 
EFFECT OF AN EDUCATIONAL PROGRAM FOR etc...

Table (3): Criteria of the Epileptic Seizures of Adolescents with Epilepsy before and Follow-up after 3 \& 6 months of Program Implementation:

\begin{tabular}{|c|c|c|c|c|c|c|c|c|c|}
\hline \multirow{2}{*}{$\begin{array}{c}\text { Epileptic Seizures } \\
\text { data }\end{array}$} & \multicolumn{2}{|c|}{ Before } & \multicolumn{2}{|c|}{ After 3 months } & \multicolumn{2}{|c|}{ After 6 months } & \multicolumn{3}{|c|}{ Wilcoxon signed rank test } \\
\hline & $\begin{array}{c}\mathrm{N} \\
(\mathrm{N}=55)\end{array}$ & $\%$ & $\begin{array}{c}\mathrm{N} \\
(\mathrm{N}=55)\end{array}$ & $\%$ & $\begin{array}{c}\mathrm{N} \\
(\mathrm{N}=55)\end{array}$ & $\%$ & $\mathbf{Z 1}$ & $\mathbf{Z 2}$ & $\mathbf{Z 3}$ \\
\hline $\begin{array}{l}\text { Awareness of aura } \\
\text { symptoms }\end{array}$ & & & & & & & \multirow{3}{*}{$\begin{array}{c}2.646 \\
0.008^{*}\end{array}$} & \multirow{3}{*}{$\begin{array}{c}2.646 \\
0.008^{*}\end{array}$} & \multirow{3}{*}{$\begin{array}{c}0.000 \\
0.100 \\
0\end{array}$} \\
\hline - Yes & 31 & 56.4 & 39 & 70.9 & 38 & 69.1 & & & \\
\hline - $\quad$ No & 24 & 43.6 & 16 & 29.1 & 17 & 30.9 & & & \\
\hline $\begin{array}{l}\text { Aura help adolescent } \\
\text { in prepare } \\
\text { him/herself for fit }\end{array}$ & $(\mathrm{N}=31)$ & & $(\mathrm{N}=39)$ & & $(\mathrm{N}=38)$ & & \multirow{3}{*}{$\begin{array}{c}1.886 \\
0.059^{*}\end{array}$} & \multirow{3}{*}{$\begin{array}{c}2.828 \\
0.005^{*}\end{array}$} & \multirow{3}{*}{$\begin{array}{l}1.414 \\
0.157\end{array}$} \\
\hline$-\quad$ Yes & 20 & 64.5 & 38 & 97.5 & 36 & 94.7 & & & \\
\hline$-\quad$ No & 11 & 35.5 & 1 & 20.5 & 2 & 5.3 & & & \\
\hline \multicolumn{7}{|l|}{ Seizures duration } & \multirow[b]{4}{*}{$\begin{array}{c}3.532 \\
0.000^{*}\end{array}$} & \multirow[b]{4}{*}{$\begin{array}{c}2.985 \\
0.003^{*}\end{array}$} & \multirow[b]{4}{*}{$\begin{array}{l}0.743 \\
0.458\end{array}$} \\
\hline$-\quad \leq 5 \mathrm{~min}$ & 36 & 65.5 & 49 & 89.1 & 50 & 90.0 & & & \\
\hline$-\quad>5 \mathrm{~min}$ & 7 & 12.7 & 6 & 10.9 & 3 & 5.4 & & & \\
\hline $\begin{array}{l}\text { - } \begin{array}{l}\text { Don't count } \\
\text { duration }\end{array} \\
\end{array}$ & 12 & 21.8 & 0 & 0.0 & 2 & 3.6 & & & \\
\hline $\begin{array}{l}\text { Frequency of } \\
\text { seizures }\end{array}$ & & & & & & & \multirow{4}{*}{$\begin{array}{c}5.038 \\
0.000^{*}\end{array}$} & \multirow{4}{*}{$\begin{array}{c}4.097 \\
0.000 *\end{array}$} & \multirow{4}{*}{$\begin{array}{l}1.291 \\
0.197\end{array}$} \\
\hline $\begin{array}{l}\text { - Once or more } \\
\text { /month }\end{array}$ & 31 & 56.4 & 39 & 70.9 & 40 & 72.7 & & & \\
\hline $\begin{array}{l}\text { - Once or more } \\
\text { /week }\end{array}$ & 19 & 34.5 & 13 & 23.6 & 11 & 20.0 & & & \\
\hline $\begin{array}{l}\text { - Once or more } \\
\text { /day }\end{array}$ & 5 & 9.1 & 3 & 5.5 & 4 & 7.3 & & & \\
\hline $\begin{array}{l}\text { Period since last } \\
\text { seizure }\end{array}$ & & & & & & & \multirow{4}{*}{$\begin{array}{c}4.617 \\
0.000^{*}\end{array}$} & \multirow{4}{*}{$\begin{array}{c}3.605 \\
0.000^{*}\end{array}$} & \multirow{4}{*}{$\begin{array}{l}1.008 \\
0.314\end{array}$} \\
\hline - Week or less & 26 & 47.3 & 20 & 63.3 & 21 & 38.2 & & & \\
\hline $\begin{array}{ll}\text { - } & \text { Month or } \\
\text { less }\end{array}$ & 27 & 49.1 & 12 & 21.8 & 14 & 25.5 & & & \\
\hline $\begin{array}{l}\text { - } \begin{array}{l}\text { More than } \\
\text { month }\end{array} \\
\end{array}$ & 2 & 3.6 & 23 & 41.9 & 20 & 36.3 & & & \\
\hline
\end{tabular}

(*) Statistically significant at $\mathrm{P}<0.05$

$\mathrm{Z} 1=$ differences between before \&post 3 months of the program implementation

$\mathrm{Z} 2=$ differences between before $\&$ post 6 months of the program implementation

$\mathrm{Z} 3=$ differences between post 3 months $\&$ post 6 months of the program implementation

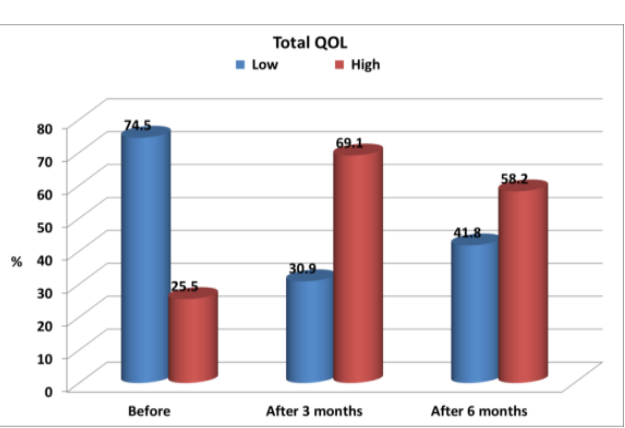

Figure (1): Total Levels of Quality of Life of the Studied Adolescents before and Follow-up after 3 and 6 months of Program Implementation

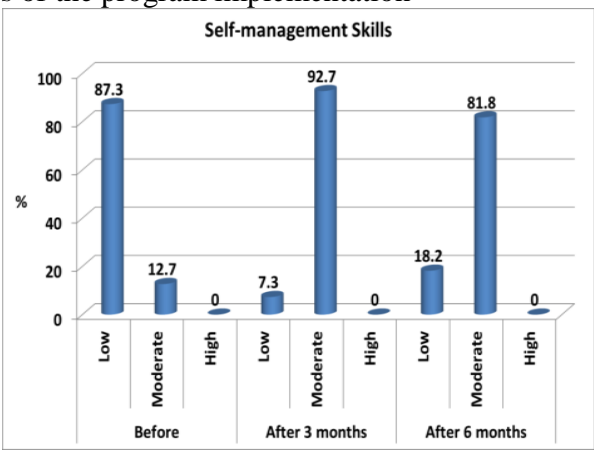

Figure (2): Total Levels of Self-

Management Skills of the Studied Adolescents before and Follow-up after 3 $\& 6$ months of Program Implementation 
Table (4): Correlation between the Adolescents' Total QOL Scores \& their Total Selfmanagement Skills before and Follow-up after $3 \& 6$ months of Program Implementation

\begin{tabular}{|c|c|c|c|c|c|c|}
\hline \multirow{2}{*}{} & \multicolumn{6}{|c|}{ Total QOI } \\
\cline { 2 - 7 } & \multicolumn{2}{|c|}{ Before } & \multicolumn{2}{c|}{ After 3 months } & \multicolumn{2}{c|}{ After 6 months } \\
\cline { 2 - 6 } & $\mathbf{R}$ & $\mathbf{P}$ & $\mathbf{R}$ & $\mathbf{P}$ & $\mathbf{R}$ & $\mathbf{P}$ \\
\hline $\begin{array}{c}\text { Total Self- } \\
\text { management } \\
\text { Skills }\end{array}$ & 0.405 & $0.002^{*}$ & 0.774 & $0.000^{*}$ & 0.761 & $0.000^{*}$ \\
\hline
\end{tabular}

(*) Statistically significant at $\mathrm{P}<0.05$.

\section{Discussion}

The findings of the current study revealed that slightly more than half of the studied adolescents were in the age 11 to less than 14 years. This finding is supported by Gunawan, Limanto\& Saharso, (2015) who conducted a study about "Age decreases quality of life in adolescents with intractable epilepsy", and reported that, epilepsy was more prevalent in early adolescence. This finding explained by the fact that this is the youngest age of adolescence stage, which is characterized by dependence on parents and obeying them in follow-up visits, while the older age of adolescents are more independent in their behaviors and activities.

The prevalence of epilepsy among subjects of the current study was slightly higher in girls than boys which are on the contrary, with most reports of gender difference in epilepsy (Eseigbe et al. 2014) who reported in their study about "The Perception of Family Function by Adolescents with Epilepsy in a Rural Nigerian Community" that the male gender is higher than girls in children with epilepsy. Also, Guven\& Isler, (2015) in their study conducted in Turkey found the same finding.

While this finding congruent with Cianchetti et al. (2015) who investigated the burden of epilepsy and its impact on the quality of life of children and adolescents and their families that, there is a higher prevalence of epilepsy in girls than boys in his study. This difference may be attributed to, the adolescent boys are more likely to become more independent and refuse at many times to visit the clinic with the parents as reported by many of them, while girls show less greater attempts to establish or maintain contact with their caregiver, so their presence in the care setting was more prevalent.

In the present study rural residents represented approximately two third of cases. This finding is in agreement with Camfield \& Camfield, (2015) who reported a high prevalence of epilepsy in rural areas of underdeveloped countries in their study about "Incidence, prevalence and etiology of seizures and epilepsy in children" they reported that epilepsy is highly prevalent in rural, illiterate group than urban and literate populations. From the researcher point of view, this finding may return to poor health care services in rural areas, either for mothers or the child leading to high incidence of birth trauma, asphyxia, intracranial infections. Also, genetic factors which are more prevalent in rural areas due to consanguineous marriage. The higher percentage of adolescents with epilepsy in the present study were reported in the first, then the second child in birth order than later children this may be due to the young age of mothers and the associated high incidence of perinatal complications. This result is similar to that reported from 
EFFECT OF AN EDUCATIONAL PROGRAM FOR etc...

Shakirullah, Ali, khan\& Nabi, (2014) they found a higher incidence of epilepsy in the first child when searching about the prevalence, incidence and etiology of epilepsy.

The majority of adolescents in the present study had generalized seizure type which is in agreement with many studies as Alshahawy et al. (2017) in his study about school children with epilepsy in Gharbia Governorate in Egypt; reported high prevalence of generalized epilepsy. This finding may be attributed to that the generalized type of epilepsy is the most terrible type of epilepsy that cause the family to seek immediately for treatment, while other types of epilepsy may give subtle or vague manifestations. The majority of adolescents in this study were receiving poly-therapy of anti-epileptic drugs which is in agreement with Monir, EL-Alameey\& Eltahlawy, (2013) in his study discussed "Health related quality of life of children with epilepsy in Egypt" and reported that, $52 \%$ of children with epilepsy were on more than one antiepileptic drug.

Regarding family history of epilepsy, the current study clarified its presence in slightly more than one quadrant of adolescents with epilepsy which was nearly similar to the study of Canpolat et al. (2014) they reported a family history of epilepsy in $33 \%$ of the children in their study on the prevalence and risk factors of epilepsy in school age children in Turkey. This finding explained by the fact that, inheritance considered a risk factor for certain type of epilepsy as confirmed by Babtain, (2013) on the study about the effect of family history of epilepsy in Saudi Arabia on the diagnosis of epilepsy.

Regarding the age of onset of epilepsy; the findings revealed that, more than half of adolescents with epilepsy below the age of 5 years has had their first epileptic seizure. This finding is congruent with the study of Sarhan, Ayouty, Elsharkawy\&
AbdElmagid, (2016) on children with epilepsy in Egypt, which reported that the highest frequency rate of epilepsy onset occurs during early and middle childhood period. Also, Farahat, El-Shafie\& AbdEl-Rasoul, (2010) reported in the study about children epilepsy management in Menoufiya governorate that, about two third of children, had their first seizure in the first 5 years of age then the percentage decreases gradually with increasing age. This finding may be explained in the light of the fact that, the developing brain of infants and children is much more sensitive to convulsive seizures when it is affected by infection, trauma, or by minimal febrile illness when compared to adults.

More than two third of the studied adolescent in the present study, stated that their seizures sustained for less than 5 minutes. This result may be similar to the study of Friedman, Donner, Stephens, Wright\& Devinsky, (2014) who reported that, seizures are mostly last for seconds to less than a five minutes and without intervention they are self-limited. Also, in the current study, nearly one fifth of adolescents didn't count the seizure duration at all. This finding may be related to parents' fear and anxiety that may accompany the unpredictable nature of the seizures which may cause them miss to count the duration of seizure or may be due to the unpredictable nature of the seizures where no witness at the time when seizures occurred. In addition, missing the count of seizure duration may be also due to nocturnal seizures that may be missed. This finding is consistent with Monir et al. (2013) who found that, less accurateness in the reporting of seizure duration by in his study.

The main aim of successful epilepsy treatment traditionally focuses on decrease the number of seizures per year reaching to complete seizure control (Gabr\& Shams, 2015). As regards the distribution 
of the studied adolescents, according to their seizure frequency and the period since the last seizure, the current study found that, there was statistically significant difference between their seizure frequency and the period since the last seizure before \& after 3 months of the program implementation. This difference from the researcher point of view may be the result of increased adolescents' awareness about the drug adherence and follow-up throughout the study. This finding was supported by Abusaad\& ElWehedy, (2016) in the study about the impact of educational sessions on mothers' adherence to AEDs and seizure severity among their children; and reported that, health education programs that stress the importance of medication adherence were more successful and produce significant decreases in seizure severity among children with epilepsy.

Adolescent's perspective and how they cope with this disease in mental, physical and social ways was the focus of the quality of life assessment scale on evaluating the health status (Gatta et al. 2014). Concerning adolescents' total quality of life scores, it is clarified that, more than two third of adolescents had "low" level of the total QOL before the program implementation, this finding may be attributed to the high seizure frequency before implementation of the educational program and supported by improvement in total QOL after $3 \& 6$ months of the program accompanied at the same time by reducing seizure frequency. This finding was supported by Cianchetti et al. (2015) stated that all aspects of QOL are impaired at different degree both in children/adolescents and their families due to epilepsy, and demonstrated that the high seizure frequency worse HRQOL in children and adolescents with epilepsy compared to those with less severe or inactive epilepsy. While, this finding is incongruent with the study of Siqueira,
Guerreiro\& Pedroso, (2011) who

showed a relatively good QOL score of Brazilian adolescents with epilepsy when assessed by QOLIE-AD-48 tool. Also, Wu et al. (2010) reported high QOL in Chinese AWE. This difference may come from different cultural, educational and economic background.

Various educational needs should be covered for adolescents with epilepsy and they must adopt many behaviors of selfmanagement to control their condition (Aliasgharpour et al. 2013). Selfmanagement skills include five areas of management these are; information management, safety management, lifestyle management, medication management and seizure management. The finding of this study revealed that, the majority of the studied adolescents had "low" selfmanagement skills before the implementation of the educational program, while after the program implementation they had "moderate" level with no one of them reach to the "high" level of self-management. It is obvious that their level improved to some extent after the program implementation confirmed by the significant difference that was present between all the study stages, but reaching to "high" level of selfmanagement may be required long periods of continuous education and follow-up. This finding was congruent with Rizou, De Gucht, Papavasillou\& Maes, (2017) who found a brief improvement in selfmanagement in adolescents suffering from epilepsy after the based intervention in his study that evaluate the effect of psychoeducational intervention on selfmanagement for children and adolescents with epilepsy in Greece.

It is proved from the current study, that there was a significant positive correlation between adolescents' total QOL and their total self-management skills before the program implementation and at the followup. This finding was congruent with 
Yadegary et al. (2015) in their study about the effect of self-management training on quality of life in patients with epilepsy was reported that, the improvement of HRQOL of patients with epilepsy is largely a result of successful epilepsy self-management practices. Also, Bautista, (2017) reported that, achieving optimal seizure control and enhancing adolescent's QOl requires practicing excellent self-management skills. This finding may be explained by the fact that, a major part of the comprehensive care for patients with chronic diseases is to increase their self-management about the disease that consequently improve their physical, psychological, social and the total quality of life for patients with epilepsy. So, training and educational programs for adolescents with epilepsy and their parents are especially important for their comprehensive management.

\section{Conclusion}

Adolescents with epilepsy had better quality of life and self-management skills after implementation of the educational program.

\section{Recommendations}

The following recommendations are to be considered:

- A routine HRQOL assessment should be applied in practice.

- Regular and continuous health educational programs are essential for adolescents with epilepsy.

\section{Acknowledgements}

All the adolescents' who participated in the study and the out-patient department staff of Mansoura University Children Hospital, we would like to thank them for their help and cooperation during the study period and appreciate the great efforts of our supervisors in this work.

\section{References}

1. Abusaad, F., and El-Wehedy, A. (2016). Impact of Educational Sessions for Epileptic Children Mothers on Their knowledge, Adherence to Antiepileptic Drugs and Seizures Severity among their Children. Journal of Nursing and Health Science (IOSR); 5 (5), Ver. III: Pages 81-89.

2. Alfstad, K.A., Torgersen, H., Vanroy, B., Hessen, E., Hansen, B.H., Henning, O. et al., (2016). Psychiatric comorbidity in children and youth with epilepsy: An association with executive dysfunction?. Epilepsy \& Behavior; 56: Pages 88-94.

3. Aliasgharpour, M., Dehgahn, N.N., Yadegary, M.A. and Haghani, H. (2013). Effects of an educational program on selfmanagement in patients with epilepsy. Seizure; 22: Pages 48-52.

4. Alshahawy, A.K., Darwish, A.H., Shalaby, S., and Mawlana, W. (2017). Prevalence of idiopathic epilepsy among school children in Gharbia Governorate, Egypt. Brain and Development; cited online 30 December 2017, Available at: http://otorhinolaryngologysfakianakis al.blogspot.com.eg/2017/12/prevalen ce-of-idiopathic-epilepsyamong.html

5. Babtain, F.A. (2013). Impact of a family history of epilepsy on the diagnosis of epilepsy in southern Saudi Arabia. Seizure; 22 (7): Pages 542-547.

6. Bautista, R.E. (2017). Understanding the self-management skills of persons with epilepsy. Epilepsy \& Behavior; 69: Pages 7 11.

7. Bell, G.S., and Liu, R.S. (2016). Provision of clinical services for people with epilepsy. UCL Institute 
Ghada Gamal Mohamed Badawy et. al.

of Neurology, National Hospital for

Neurology and Neurosurgery;

chapter 57. Available at:

https://www.epilepsysociety.org.uk/si

tes/default/files/attachments/Chapter

57BellLiu2015.pdf

8. Camfield, $P$. and Camfield, C. (2015). Incidence, prevalence and etiology of seizures and epilepsy in children. Epileptic Disorders; 17 (2): Pages 117-123.

9. Canpolat, M., Kumandas, S., Poyrazoglu, H.G., Gumus, H., Elmali, F., and Per, H. (2014). Prevalence and risk factors of epilepsy among school children in Kayseri City Center, an urban area in Central Anatolia, Turkey. Seizure; 23 (9): Pages 708-716.

10. Cianchetti, C., Messina, P., Pupillo, E., Crichiutti, G., Baglietto, Giuseppina, M. et al. (2015). The Perceived burden of epilepsy: impact on the quality of life of children and adolescents and their families. Seizure; 24: Pages 93-101.

11. Cramer, J.A., Westbrook, L.E., Devinsky, O., Perrine, K., Glassman, M.B., Camfield C. (1999). Development of the Quality of Life in Epilepsy Inventory for Adolescents: the QOLIE-AD48. Epilepsia; 40: Pages 1114-1121.

12. Dilorio, C., Shafer, P., Letz, R., Henry, T., Schomer, D., Yeager, K. (2004). Project EASE: A study to test a psychosocial model of epilepsy medication management. Epilepsy \& Behavior,5(6), 926-936.

13. Eseigbe, E.E., Nuhu, F.T., Sheikh, T.L., Adama, S.J., Eseigbe, P., and Oguizu, O.J. (2014). The Perception of Family Function by Adolescents with Epilepsy in a Rural Nigerian Community. Epilepsy Research and Treatment; Volume 2014, Article ID 959274, 6 pages. Available online at: http://dx.doi.org/10.1155/2014/95927 4

14. Farahat, T.M., El-Shafie, A.M., and Abd-El-Rasoul, G.M. (2010). Integrated Management of Epilepsy among Basic School Children in Menoufiya Governorate. Egypt Journal of Neurol Psychiatry Neurosurgry; 47 (1), Pages 49-58.

15. Friedman, D., Donner, E.J., Stephens, D., Wright, C., and Devinsky, O., (2014). Sudden unexpected death in epilepsy: Knowledge and experience among U.S. and Canadian neurologists. Epilepsy \& Behavior; 35: Pages 13 18.

16. Gabr, W.M., and Shams, M.E. (2015). Adherence to medication among outpatient adolescents with epilepsy. Saudi Pharm; 23(1): Pages 33-40.

17. Gatta, M., Balottin, L., Salmaso, A., Stucchi, M., De Carlo, D., Guarneri, E. et al. (2014).

Psychopathology, quality of life and risk factors in children and adolescents with recent-onset epilepsy. Minerva Pediatrica; 69(1): Pages 1-14.

18. Gavvala, J.R., and Schuele, S.U. (2016). Epilepsy. Journal of the American Medical Association (JAMA); 316(24), Page 2686.

19. Gunawan, P.I., Limanto, TH.L., and Saharso, D. (2015). Age decreases quality of life in adolescents with intractable epilepsy. Universa Medicina; 34 (2).

20. Guven, S.T., and Isler, A. (2015). Validity and Reliability of the Seizure Self-Efficacy Scale for Children with Epilepsy. Archives of Neuropsychiatry; 52(1): Pages 4753.

21. Kerr, C., Nixon, A., Angalakuditi, M. (2011). The impact of epilepsy on children and adult patients' lives: 
development of a conceptual model from qualitative literature. Seizure; 20(10):764-74.

22. Lewis, SH., Noyes, J., Hastings, R.P. (2014). Systematic review of epilepsy. Self-management interventions integrated with a synthesis of children and young people's views and experiences. Advanced Nursing; 71: Pages 478497.

23. Rizou, L., De Gucht, V., Papavasiliou, A., Maes, S. (2017). Evaluation of a self-regulation based psycho-educational pilot intervention targeting children and adolescents with epilepsy in Greece. Seizure;50, Pages 137-143.

24. Monir, Z.M., EL-Alameey, I.R. and Eltahlawy, E. (2013). Health related quality of life of children with epilepsy in Egypt. Journal of the Arab Society for Medical Research; 8: Pages 53-66.

25. Sarhan, A.A., Ayouty, M.M., Elsharkawy, A.A., and AbdElmagid, D.S. (2016). Neurodevelopmental and neurobehavioral aspects of childhood epilepsy. Benha Medical Journal; 32: Pages 13-19.
26. Shakirullah, Ali N., khan A, Nabi M., (2014). The Prevalence, Incidence and Etiology of Epilepsy. International Journal of Clinical and Experimental Neurology: 2(2): Pages 29-39.

27. Siqueira, N.F., Guerreiro, M.M., and Pedroso, E.A., (2011). Selfesteem, social support perception and seizure controllability perception in adolescents with epilepsy. Arquivos de Neuro-Psiquiatria; vol.69 no.5.

28. Smith, PH., E and Wallace, SH., J. (2016). Taking Over Epilepsy From The Pediatric Neurologist. Neurol Neurosurgery Psychiatry;74(I): Pages I37-I41.

29. Wilson, E.V. (2017). Engaging young people with a chronic illness. AustFam Physician; 46(8): Pages 572-76.

30. Yadegary, M.A., Maemodan, F.G., Nayeri, N.D., Ghanjekhanlo, A. (2015). The effect of selfmanagement training on healthrelated quality of life in patients with epilepsy. Epilepsy\& Behavior; 50: Pages 108-12.

31. Zashikhina, A., and Hagglof, B. (2014). Health-related quality of life in adolescents with chronic physical illness in northern Russia: a crosssectional study Health and Quality of Life Outcomes. Bio-Medical Central; 12(12). 